\title{
Genome-Wide Association Mapping of Prostrate/Erect Growth Habit in Winter Durum Wheat
}

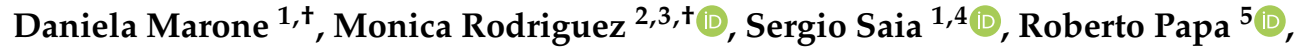 \\ Domenico Rau ${ }^{2}$, Ivano Pecorella ${ }^{1}$, Giovanni Laidò ${ }^{1}$, Nicola Pecchioni ${ }^{1}$ D, Julia Lafferty ${ }^{6}$, \\ Matthias Rapp ${ }^{7}$, Friedrich H. Longin ${ }^{7}$ and Pasquale De Vita ${ }^{1, *(\mathbb{D})}$ \\ 1 Research Centre for Cereal and Industrial Crops, CREA, SS 673, km 25.200, 71122 Foggia, Italy; \\ daniela.marone@crea.gov.it (D.M.); sergio.saia@crea.gov.it (S.S.); ivano.pecorella@gmail.com (I.P.); \\ Giovanni.lai79@libero.it (G.L.); nicola.pecchioni@crea.gov.it (N.P.) \\ 2 Department of Agriculture, University of Sassari, Via E. de Nicola, 14, 07100 Sassari, Italy; \\ mrodrig@uniss.it (M.R.); dmrau@uniss.it (D.R.) \\ 3 Centro per la Conservazione e Valorizzazione della Biodiversità Vegetale, Università degli Studi \\ di Sassari, SS 127bis, km 28.500 Surigheddu, 07041 Alghero, Italy \\ 4 Research Centre for Cereal and Industrial Crops, CREA, SS 11, km 2.500, 13100 Vercelli, Italy \\ 5 Department of Agricultural, Food and Environmental Sciences, Università Politecnica delle Marche, \\ Via Brecce Bianche, 60131 Ancona, Italy; rpapa@univpm.it \\ 6 Saatzucht Donau GesmbH \& CoKG, Saatzuchtstrasse 11, A-2301 Probstdorf, Austria; \\ julia.lafferty@saatzucht-donau.at \\ 7 State Plant Breeding Institute, University of Hohenheim, Fruwirthstraße 21, 70593 Stuttgart, Germany; \\ Matthias_Rapp@uni-hohenheim.de (M.R.); Friedrich.Longin@uni-hohenheim.de (F.H.L.) \\ * Correspondence: pasquale.devita@crea.gov.it; Tel.: +39-0881-714911 \\ + These authors equally contributed to this work.
}

Received: 5 December 2019; Accepted: 6 January 2020; Published: 8 January 2020 updates

\begin{abstract}
By selecting for prostrate growth habit of the juvenile phase of the cycle, durum wheat cultivars could be developed with improved competitive ability against weeds, and better soil coverage to reduce the soil water lost by evaporation. A panel of 184 durum wheat (Triticum turgidum subsp. durum) genotypes, previously genotyped with DArT-seq markers, was used to perform association mapping analysis of prostrate/erect growth habit trait and to identify candidate genes. Phenotypic data of plant growth habit were recorded during three consecutive growing seasons (2014-2016), two different growth conditions (field trial and greenhouse) and two sowing periods (autumn and spring). Genome-wide association study revealed significant marker-trait associations, twelve of which were specific for a single environment/year, 4 consistent in two environments, and two MTAs for the LSmeans were identified across all environments, on chromosomes 2B and 5A. The co-localization of some MTAs identified in this study with known vernalization and photoperiod genes demonstrated that the sensitivity to vernalization and photoperiod response are actually not only key components of spring/winter growth habit, but they play also an important role in defining the magnitude of the tiller angle during the tillering stage. Many zinc-finger transcription factors, such as $\mathrm{C} 2 \mathrm{H} 2$ or $\mathrm{CCCH}$-domain zinc finger proteins, known to be involved in plant growth habit and in leaf angle regulation were found as among the most likely candidate genes. The highest numbers of candidate genes putatively related to the trait were found on chromosomes 3A, 4B, 5A and 6A. Moreover, a bioinformatic approach has been considered to search for functional ortholog genes in wheat by using the sequence of rice and barley tiller angle-related genes. The information generated could be used to improve the understanding of the mechanisms that regulate the prostrate/erect growth habit in wheat and the adaptive potential of durum wheat under resource-limited environmental conditions.
\end{abstract}

Keywords: durum wheat; juvenile growth habit; tiller angle; QTL; candidate gene 


\section{Introduction}

Plant architecture integrates a set of important agronomic traits in wheat, such as plant height, tiller number, juvenile growth habit, flag leaf angle and spike characteristics, that are important for increasing crop yield potential. Plant breeders have extensively modulated such architectural traits: the extraordinary increase in wheat yield that has been registered with the introduction of modern semi-dwarf wheat varieties during green revolution was partially due to the improvement of the plant architecture [1], e.g., in terms of plant height [2] and flag leaf angle [3].

Durum wheat (Triticum turgidum subsp. durum) is grown on 8 to $10 \%$ of all the wheat cultivated area in the world and is an economically important crop in the Mediterranean area where it represents one of the most important agricultural crops. Changes in global average temperature, precipitation regime and increase of atmospheric $\mathrm{CO}_{2}$ concentration will impact the crop productions at various rates in different parts of the world, particularly in those areas, such as the Mediterranean basin, already considered as one of the most critical and vulnerable geographic zones [4]. Therefore, it is important to increase the knowledge of durum wheat plant architecture, in terms of size, shape and orientation of the shoot, to improve the yield performances of durum wheat under the effect of ongoing climate change [5] and increase its ability to rapidly cover the soil, that is directly related to both yield and competitivity against weeds [6].

Tillering, or the production of lateral branches (i.e., culms), is a key component of yield for straw cereals such as rice, barley, bread and durum wheat $([7,8]$ and reference therein), given that the number of tillers affects the number of fertile spikes and consequently the kernel numbers per unit area. So, selecting cultivars with moderate-to-high tillering ability represents an important breeding objective. However, for monocotyledonous crops, the dynamics of tiller angle from vertical, during the juvenile growth stage (i.e., from prostrate to semi-prostrate and erect growth habit) is another important agronomic trait that should be considered, because a dense ground cover affects the interception of light for photosynthetic accumulation, the inhibition of weed growth and the reduction of water evaporation from soil [9].

Rice varieties show large variation in tiller angle, as a complex quantitative trait, the genetic bases of which have been extensively investigated using quantitative trait loci (QTL) analysis [10-12]. Several underlying genes, including LAZY1 (LA1), PROG1 (Prostrate Growth 1), DWARF4, and TAC1 (Tiller Angle Control 1), associated with tiller angle, have been cloned through map-based cloning, and the molecular basis has been clearly elucidated [13-16].

In barley, plants possessing the semi-dwarfing $s d w 1 / d e n s o$ gene are characterized by prostrate growth, whereas plants with its dominant allele are characterized by erect growth providing an effective morphological marker of this gene. Further analysis revealed that barley sdw/denso gene, an ortholog of the rice SD1 gene [17], is located on chromosome $3 \mathrm{H}$ based on the barley reference genome sequence and has a pleiotropic effect on several agronomic traits such as plant height, heading and flowering time [18]. Other QTLs that determined the prostrate/erect growth habit in Hordeum spontaneum have been found on the long arm of chromosomes $1 \mathrm{H}, 3 \mathrm{H}$ and $6 \mathrm{H}$, with that on chromosome $3 \mathrm{H}$ located in the same region of sdw1/denso gene locus [19].

Studies carried out on wheat are instead very limited. In the past, Li et al. [20] found few specific QTLs for juvenile growth habit in wheat, as a quantitative trait associated with other morphological traits. In particular, they found three regions on 6AS, 1DS and 2DS controlling tiller number that also influenced prostrate/erect growth habit. More recently, a genomic wide association study (GWAS) has been conducted for seedling habit, together with other important agronomic traits, and significant marker-trait associations (MTAs) have been found for this trait on chromosomes 3B, 4A and 6B [21]. Significant MTAs for the prostrate/erect trait have also been identified in durum wheat: Giraldo et al. [22] found two chromosome regions on 3A and 3BL, significantly associated to plant juvenile growth habit in tetraploid wheats (T. durum and T. dicoccum). In the case of barley, the close association existing between the semi-dwarfing $s d w 1 / d e n s o$ gene regulating plant height and 
the prostrate growth habit could be explained by the pleiotropic effect of $s d w 1 / d e n s o$ gene on tiller angle [23].

The prostrate/erect growth type, as flowering, is known to be highly influenced by environmental conditions such as temperature and day-length [24]. This also means that adaptation genes such as $V r n$ and $P p d$ could influence the expression of juvenile growth habit trait either because in linkage, or because exert a pleiotropic effect on this trait [25]. Also freezing tolerance coupled to winter growth habit was found to be associated with prostrate growth type in wheat; a gene controlling prostrate growth was found to be closely linked with Fr1-Vrn1 locus on chromosome 5A in the pioneering study of Roberts [26] about the genetic control of such traits. However, prostrate growth type can also be found in cultivars with low vernalization requirements but high photoperiod response, indicating since the early studies that sensitivity to vernalization and photoperiod are the two major components associated to tiller angle from vertical during the juvenile growth stage in wheat [27].

In the light of these considerations, it is therefore useful to dissect the genetic and molecular bases underlying the plant juvenile growth habit in terms of tiller angle, possibly in relation to major adaptation loci, being this trait very important in determining plant architecture and influencing yield component traits. The rapid advances in genotyping technologies enabled genotyping-by-sequencing (GBS) also in durum wheat, generating a density of genome-wide markers. The GBS platform of DArT-seq (Diversity Array Technology DArT, Canberra, Australia) allows for the selection of genome fractions that predominantly correspond to active genes. Association mapping (AM), also known as linkage disequilibrium (LD) mapping, is a powerful and promising tool for gene detection in crop plants [28]. Different traits have been genetically dissected in tetraploid wheat by means of this approach, such as root traits [29-33], resistance against stem rust, leaf rust and stripe rust [21,34-36], resistance to Fusarium Head Bligth (FHB) [37], various agronomic traits, biomass and yield components [38-40], and yellow pigment content [41].

With the longer-term aim of selecting genotypes with a desirable plant architecture to be used in durum wheat breeding, the aim of this study was to perform association mapping for prostrate/erect growth habit trait in a panel of 170 diverse winter and 14 spring durum wheat genotypes, previously genotyped with DArT-seq markers [42], and to identify candidate genes based on available sequences of markers located at the MTAs, in order to provide valuable information for better understanding the genetic mechanism of the tiller angle trait in wheat. Moreover, a bioinformatic approach has been pursued, to search for functional homologous genes in wheat by using the sequence of genes previously identified in other cereal species and found to be associated with tiller angle, namely PROG1, TAC1, $L A Z Y 1$ and $S D 1$ in rice.

\section{Results}

\subsection{Phenotypic Variation for the Trait}

The statistical parameters of the plant growth habit for each environment are shown in Tables 1 and 2. Phenotypic means ranged from 3.46 in FF14 (the first letter of the abbreviation of each experiment is for the sites, the second is for the kind of experiment and the number is for the cropping season, see Section 4.2 for a complete explanation. FF14 is for Foggia in the field in 2014) to 6.90 in HF14 (Hohenheim in the field 2014), with a grand mean of 5.06. All distributions were slightly platykurtic, except for PF13 (Probstdorf in the field 2013) and genotypic means (expressed as G LS means) that showed a relatively low kurtosys $(-1.78$ and -1.50 , respectively). Broad sense heritability was very high and ranged from 0.79 in PF13 to 0.99 in FG15 (Foggia in the Greenhouse in 2015), indicating a tight genetic control (Table 1). Genotypes and Genotypes $\times$ Environment $(\mathrm{G} \times \mathrm{E})$ were significant at $p \leq 0.001$, making possible analyses for single environment (Table 2). Best linear unbiased predictions (BLUPs) were then used to confirm results of marker-trait associations. Skewness of the habit distribution in all environments, $G$ mean, and $G \times E$ distributions were scarcely left-skewed, except for the environment HF14, which was moderately left-skewed (Figure 1). Mean values across locations, 
LSmeans (both across locations and by genotype $\times$ environment) and, correlations $(r)$ coefficients calculated for determining the relations for the average values of the various environments, are given in Supplemental Table S1.

Table 1. Descriptive statistics of the prostrate/erect growth habit (1 for completely erect, 9 for completely prostrate) in the environments under study.

\begin{tabular}{|c|c|c|c|c|c|c|c|c|}
\hline & FF14 & FF15 & FF16 & FG15 & HF14 & PF13 & $\begin{array}{l}\text { TOT (G } \\
\text { LSmeans) }\end{array}$ & TOT $(\mathrm{G} \times \mathrm{E})$ \\
\hline Mean & 3.46 & 5.17 & 4.54 & 4.93 & 6.90 & 4.86 & 5.06 & 4.97 \\
\hline Standard Error & 0.25 & 0.10 & 0.12 & 0.11 & 0.25 & 0.27 & 0.13 & 0.08 \\
\hline Coefficient of Variation & 80.4 & 27.3 & 34.5 & 28.6 & 40.4 & 66.8 & 33.9 & 48.4 \\
\hline$\sigma_{G}^{2}$ & n.a. & 5.05 & 7.35 & 3.65 & 15.55 & 14.02 & n.a. & 30.29 \\
\hline $\mathrm{F}$ & n.a. & 4.05 & 16.26 & 18.46 & 45.38 & 9.94 & n.a. & 10.69 \\
\hline $\mathrm{P}$ & n.a. & $<0001$ & $<0001$ & $<0001$ & $<0001$ & $<0001$ & n.a. & $<0001$ \\
\hline Kurtosis & -1.01 & -0.37 & -0.43 & -0.08 & -0.12 & -1.78 & -1.40 & -0.93 \\
\hline Skewness & 0.61 & 0.06 & -0.46 & -0.21 & -1.28 & 0.08 & -0.28 & -0.06 \\
\hline Min & 1.0 & 1.0 & 1.0 & 1.0 & 1.0 & 1.0 & 1.7 & 1.0 \\
\hline Max & 9.0 & 8.7 & 9.0 & 8.0 & 9.0 & 9.0 & 8.2 & 9.0 \\
\hline Range & 8.0 & 7.7 & 8.0 & 7.0 & 8.0 & 8.0 & 6.5 & 8.0 \\
\hline $\begin{array}{c}\mathrm{h}^{2}{ }_{\mathrm{B}} \text { with covariance structure } \\
\text { (Mixed Model) }\end{array}$ & n.a. & 0.997 & 0.998 & 0.999 & 0.999 & 0.991 & n.a. & 0.910 \\
\hline $\mathrm{h}^{2}{ }_{\mathrm{B}}$ with fixed effects (GLM) & n.a. & 0.941 & 0.903 & 0.999 & 0.978 & 0.793 & n.a. & 0.652 \\
\hline
\end{tabular}

n.a, not applicable; FF14, Foggia 2013-2014; FF15, Foggia 2014-2015; FF16, Foggia 2015-2016; FG15, Foggia greenhouse experiment 2015; HF14, Hohenheim 2014-2015; PF13, Probstdorf 2013-2014; TOT for total distribution by means of genotypic means across sites (G LSmeans, i.e., least squared means of the genotype) and genotypic values in all environments $(\mathrm{G} \times \mathrm{E})$.

Table 2. Results of analysis of variance with type 3 error [degrees of freedom (df), Habit mean squares (MS) and $p$ ] and Covariance parameter estimate (Cov) for the computation of the $\mathrm{h}^{2}$ across environments from the mixed model when including all treatments in the covariance structure for growth habit (1 for completely erect, 9 for completely prostrate) across environments.

\begin{tabular}{ccccc}
\hline Source of Variation & df & Habit MS & $p$ & Cov \\
\hline Environment (E) & 5 & 92.005 & $<0001$ & 0.315 \\
Blocks within & 7 & 2.080 & 0.0048 & 0.010 \\
Environment & 182 & 30.287 & $<0001$ & 3.124 \\
Genotype (G) & 899 & 3.082 & $<0001$ & 1.191 \\
G $\times$ E & 1229 & 0.708 & - & 0.708 \\
Error &
\end{tabular}




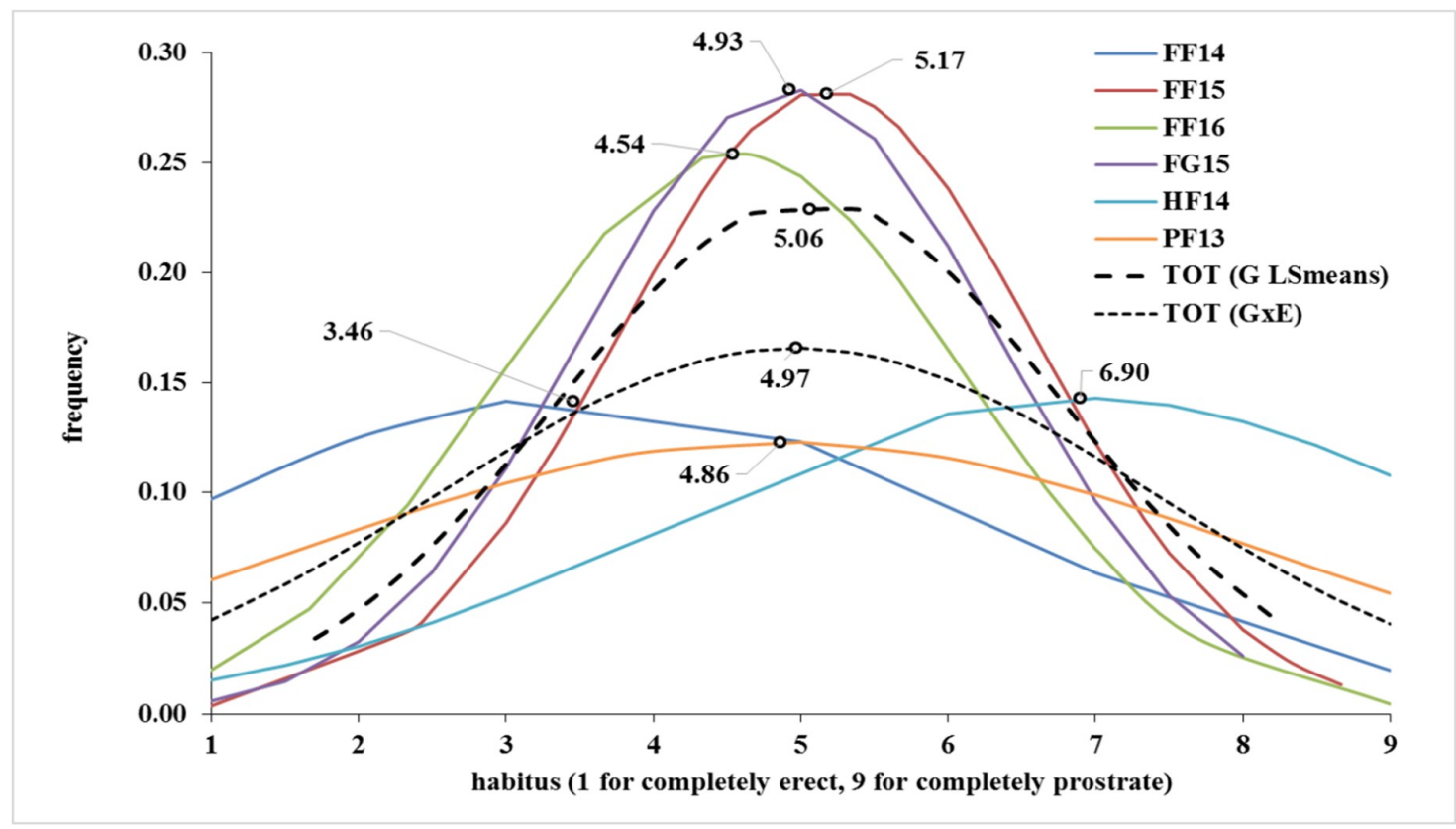

Figure 1. Probability density function (PDF) of the growth habit in the environments under study. TOT for total distribution by means of genotypic means across sites (G LSmeans, i.e., least squared means of a given genotype across environments) and genotypic values in all environments $(G \times E)$ mean value of each genotype in each environment). Open points indicate the mean of each distribution.

\subsection{Population Structure and Association Mapping}

The population structure determined on the 184 durum wheat genotypes by means of the 30,611 DArT-seq markers by STRUCTURE and DAPC approaches (Supplemental Figures S1 and S2), both evidenced the presence of four genetic groups named G1, G2, G3 and G4, in addition to the admixed group. It clearly showed that each group was different from others and that group G3 contains almost all spring genotypes, mixed with winter types (Supplemental Figure S1).

A high correlation between results from the two methods was found when considering the attribution of the different genotypes to each group $\left(\chi^{2}=386.001, p<0.0001\right)$.

Genome-wide association analysis of the prostrate/erect growth habit at the tillering stage evidenced different MTAs for the LSmeans across all environments (Figure 2), as for the mean values of each single environment (Figure 3). The results of the genome scans for the tiller angle/juvenile growth habit trait were summarized in Table 3, Figures 2 and 3, where only significant MTAs (above Bonferrroni threshold) are highlighted. Q-Q plots in Figures 2 and 3 showed as the model well fitted the data, with observed values (markers/dots) being very close to the predicted values (straight line).

When LSmeans from all the environments were investigated, only two MTAs were detected, one on chromosome 2B (D1202558), and the second hit was among the unmapped markers (D2277949), explaining $16 \%$ and $21 \%$ of phenotypic variance, respectively (Table 3, Figure 2 ).

Considering the single environments, a total of 27 MTAs was detected for prostrate/erect habit on all chromosomes, except for chromosome 1A, 1B and 5B. Some markers were found to be associated to the trait when evaluated in more than one site/year, and/or when considering the LSmean values. In particular, D1202558 marker on chromosome 2B was in common to FF14, FF15 (two different years and sowing periods) and LSmeans values, and D1665929 on 4A was found in FF14 and FG15, both characterized by a spring sowing time. The detected QTLs were represented by single markers and only the regions identified on chromosomes 5A (for HF14 and FG15), 2B (for FF14, FF15, PF13 and LSmeans), and 4B (for HF14 and FG15) were found associated to a set of closely linked markers (Table 3). Nevertheless, each QTL-tagging marker was co-mapping with many other DArT-seq and DArT markers, according to the consensus wheat map version 4.0 available on Triticarte website 
(https://www.diversityarrays.com/technology-and-resources/genetic-maps/). In particular, single MTAs were detected in single environments on chromosomes 2A (FF16), 2B (HF14), 3A (PF13), 6A (FF14), 6B (HF14), and 7B (PF13). Moreover, two distinct regions from different environments were identified on chromosomes $2 \mathrm{~B}, 3 \mathrm{~B}, 4 \mathrm{~A}, 4 \mathrm{~B}$ and 7A. Finally, a group of nine markers for which no map information was available, showed association to the growth habit, all identified in a specific environment.

The unmapped MTAs were conditionally located on the genome by means of LD between the unmapped and mapped DArT-seq markers positioned on the wheat consensus map. The LD was previously assessed [42] using 30,475 DArT-seq markers mapped on the wheat consensus map available on Triticarte website, using PLINK 1.07 (http://pngu.mgh.harvard.edu/purcell/plink/; [43]). Taking into account the LD decay estimated by Sieber et al. [42] a threshold around $2-5 \mathrm{cM}$ within chromosome, was considered. On the basis of these results, we can putatively locate the MTAs D4004513 and D1744736, both significant in HF14, on the chromosome 6B in complete LD $\left(\mathrm{r}^{2}=1\right)$ with S2258653 $(41.5 \mathrm{cM})$ located in the same region where the MTA D2289020 has been identified $(36.8 \mathrm{cM})$. The marker D3946194 was in LD with a group of markers such as D3024894, also positioned on 6B but in a different region $(65 \mathrm{cM})$ with respect to the MTA D2289020. Other unmapped MTAs can be putatively located in regions already targeted in this work, such as D2277949 which is in LD with D2276320 (mapped on 5A at $167.7 \mathrm{cM}$ ), and D3935715 and D3533805 both in LD with the MTA D2295851 (mapped on 7A at $32.3 \mathrm{cM}$ ). Finally, the marker S984195 was in LD with $\mathrm{S} 1065494$ (mapped on 7B at $95.8 \mathrm{cM}$ ) which is very far from the other MTA here identified on the same chromosome (D1112046 at $184.4 \mathrm{cM}$ ). Therefore, two new regions (D3946194 and S984195 putatively located at 65 and $95.8 \mathrm{cM}$ on chromosome $6 \mathrm{~B}$ and $7 \mathrm{~B}$, respectively) can be suggested as likely associated to the prostrate/erect growth habit, whereas any genetic position has been assumed for the two remaining unmapped MTAs (D3944539 and S1218298).

Interestingly, when we searched for any association between the MTAs identified in this work and known genes from literature (i.e., $V r n, P p d$ and $R h t$ ), we found two DArT-seq (D1202558 and D1031337) that mapped on chromosomes $2 \mathrm{~B}($ at $62.3 \mathrm{cM})$ and 7A (at $91.8 \mathrm{cM})$ respectively, in the same region where Ppd-B1 (based on marker wPt-7695 at $62.39 \mathrm{cM}$ ) and $V r n-A 3$ (wPt-9314 at $89.52 \mathrm{cM}$ ) were located, according to common markers reported by Maccaferri et al. [44] and Le Gouis et al. [45]. The MTAs identified by the markers D1395268 and D1720107 on 4B (at 133.6 and $138.3 \mathrm{cM}$, respectively) could correspond to the gene Vrn-B2, that was mapped close to wPt-5265 (at $148.34 \mathrm{cM}$ ) as reported by Le Gouis et al. [45]. Comparing the position of this DArT marker with that of common markers (wPt-3608, IWA5358 and Xbarc193) reported in other maps [44,46], the region could be the same of or very close to $V r n-B 2$. Moreover, the second region on 4BS associated to plant growth habit was verified for correspondence to the dwarfing gene Rht-B1. As reported by He et al. [47], Rht-B1 mapped very close to the DArT-seq D3064743, that was at $50 \mathrm{cM}$ far from the MTA D1110414 here identified on 4BS according to the wheat consensus map on Triticarte website. Finally, the region identified on chromosome $5 \mathrm{~A}$ by multiple associations corresponded to the gene $\mathrm{Vrn}-\mathrm{A1}$, mapped on a durum wheat linkage map constructed by using the same DArT-seq array used to genotype our collection [8].

Considering that several MTAs for growth habit mapped on chromosome $5 \mathrm{~A}$ near to the vernalization gene, as also the unmapped MTA D2277949, significant in all environments, putatively locate on chromosome 5A at $167.7 \mathrm{cM}$ (based on the LD with D2276320), we gained an insight into this region to better understand its role in the expression of both frost tolerance and growth habit. Results from GWAS using mixed linear model (MLM) showed a main association peak for frost tolerance trait in a range between 106.91 and 114.89 with the top single-nucleotide polymorphism (SNP) (D1111190, $p=5.34 \times 10^{-13}$ ) located at $111.66 \mathrm{cM}$ (Figure $4 \mathrm{~A}$ ). The association peak for tiller angle was located between 164.32 and $168.65 \mathrm{cM}$ with its top SNP (D2276320, $p=8.68 \times 10^{-10}$ ) at $167.75 \mathrm{cM}$ (Figure 4B). A second smaller peak that did not reach the significance $\left(p=7.54 \times 10^{-6}\right)$ was visible on the left with a top SNP at $111.66 \mathrm{cM}$. We then decided to use the top SNP for frost tolerance as a cofactor in a second MLM association analysis for growth habit recorded at Hohenheim (HF14). The results show that the main peak for growth habit is still present at $167.75 \mathrm{cM}$ with a strong reduction of the 
smaller peak at $111.66 \mathrm{cM}$ (Figure $4 \mathrm{C}$ ). This suggested that two different regions were likely implicated in the expression of these two traits and that the MTA D1111190 correspond to the locus Fr-A2 on chromosome $5 \mathrm{~A}$ as previously reported by Sieber et al. [42].

Table 3. Summary of the MTAs identified with FarnCPU.

\begin{tabular}{|c|c|c|c|c|c|c|}
\hline Marker & Environment & Chr & $\mathbf{c M}$ & $p$ Value & PEV * & Literature \\
\hline \multirow[t]{2}{*}{ S1133336 } & FF16 & $2 \mathrm{~A}$ & 217.7 & $2.22 \times 10^{-07}$ & 0.15 & \\
\hline & FF14 & $2 B$ & 62.3 & $2.15 \times 10^{-11}$ & 0.27 & $P p d-B 1$ \\
\hline \multirow[t]{2}{*}{ D1202558 } & FF15 & $2 B$ & 62.3 & $6.30 \times 10^{-11}$ & 0.10 & Ppd-B1 \\
\hline & LSmeans & 2B & 62.3 & $1.26 \times 10^{-10}$ & 0.16 & Ppd-B1 \\
\hline D2294169 & PF13 & $2 B$ & 65.1 & $9.91 \times 10^{-09}$ & 0.12 & Ppd-B1 \\
\hline D1137224 & HF14 & $2 B$ & 120.3 & $2.07 \times 10^{-07}$ & 0.05 & \\
\hline D1271842 & PF13 & $3 \mathrm{~A}$ & 2.7 & $8.54 \times 10^{-08}$ & 0.11 & \\
\hline D1266232 & HF14 & $3 B$ & 23.9 & $4.73 \times 10^{-08}$ & 0.04 & \\
\hline S1049173 & FG15 & $3 B$ & 71.8 & $7.11 \times 10^{-09}$ & 0.07 & \\
\hline \multirow{2}{*}{ D1665929 } & FF14 & $4 \mathrm{~A}$ & 37.2 & $1.39 \times 10^{-06}$ & 0.24 & \\
\hline & FG15 & $4 \mathrm{~A}$ & 37.2 & $1.80 \times 10^{-07}$ & 0.06 & \\
\hline D1110414 & FF14 & $4 \mathrm{~B}$ & 0 & $2.77 \times 10^{-07}$ & 0.25 & \\
\hline D1395268 & HF14 & $4 \mathrm{~B}$ & 133.6 & $4.83 \times 10^{-07}$ & 0.01 & $V r n-B 2$ \\
\hline D1720107 & FG15 & $4 \mathrm{~B}$ & 138.4 & $7.89 \times 10^{-07}$ & 0.07 & Vrn-B2 \\
\hline D2276320 & HF14 & $5 \mathrm{~A}$ & 167.7 & $4.51 \times 10^{-07}$ & 0.51 & Vrn-A1 \\
\hline D1721703 & FF14 & $5 \mathrm{~A}$ & 168.6 & $2.48 \times 10^{-08}$ & 0.03 & Vrn-A1 \\
\hline D1076422 & FF14 & $6 \mathrm{~A}$ & 188.7 & $1.57 \times 10^{-11}$ & 0.20 & \\
\hline D2289020 & HF14 & $6 \mathrm{~B}$ & 36.8 & $3.92 \times 10^{-12}$ & 0.22 & \\
\hline D2295851 & HF14 & $7 \mathrm{~A}$ & 32.3 & $2.74 \times 10^{-07}$ & 0.08 & \\
\hline D1031337 & FF14 & $7 \mathrm{~A}$ & 91.8 & $2.05 \times 10^{-07}$ & 0.22 & $V r n-A 3$ \\
\hline D1112046 & PF13 & $7 \mathrm{~B}$ & 184.4 & $8.66 \times 10^{-11}$ & 0.08 & \\
\hline D4004513 & HF14 & unmapped & & $5.56 \times 10^{-07}$ & 0.18 & \\
\hline D1744736 & HF14 & unmapped & & $2.28 \times 10^{-08}$ & 0.19 & \\
\hline D3944539 & FG15 & unmapped & & $6.76 \times 10^{-07}$ & 0.04 & \\
\hline D3946194 & HF14 & unmapped & & $3.54 \times 10^{-07}$ & 0.18 & \\
\hline D2277949 & LSmeans & unmapped & & $2.07 \times 10^{-08}$ & 0.21 & \\
\hline D3935715 & HF14 & unmapped & & $2.60 \times 10^{-09}$ & 0.12 & \\
\hline D3533805 & HF14 & unmapped & & $2.74 \times 10^{-07}$ & 0.08 & \\
\hline S984195 & FF14 & unmapped & & $4.83 \times 10^{-07}$ & 0.03 & \\
\hline S1218298 & HF14 & unmapped & & $2.50 \times 10^{-08}$ & 0.10 & \\
\hline
\end{tabular}

* PEV $=$ Proportion of Explained Variance. Considering that Circulating Probability Unification (FarmCPU) does not provide the proportion of explained phenotypic variance for each MTA, we here report the adjusted $\mathrm{R}^{2}$ values for each significant SNP that were calculated using the $\operatorname{lm}()$ function in R. In bold, the SNP markers associated with the prostrate/erect growth habit in all environments through the calculation of the LSmeans.
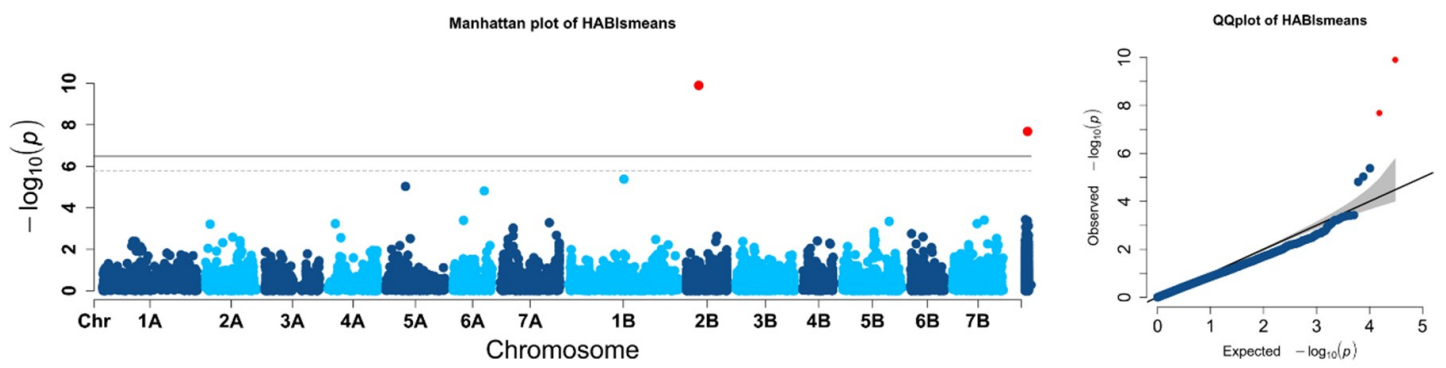

Figure 2. Manhattan plot showing the chromosome location of significant marker-trait associations for prostrate growth habit inputted as the LSmeans across the six environments. Significant MTAs are highlighted in red $(p \leq 0.01)$. 

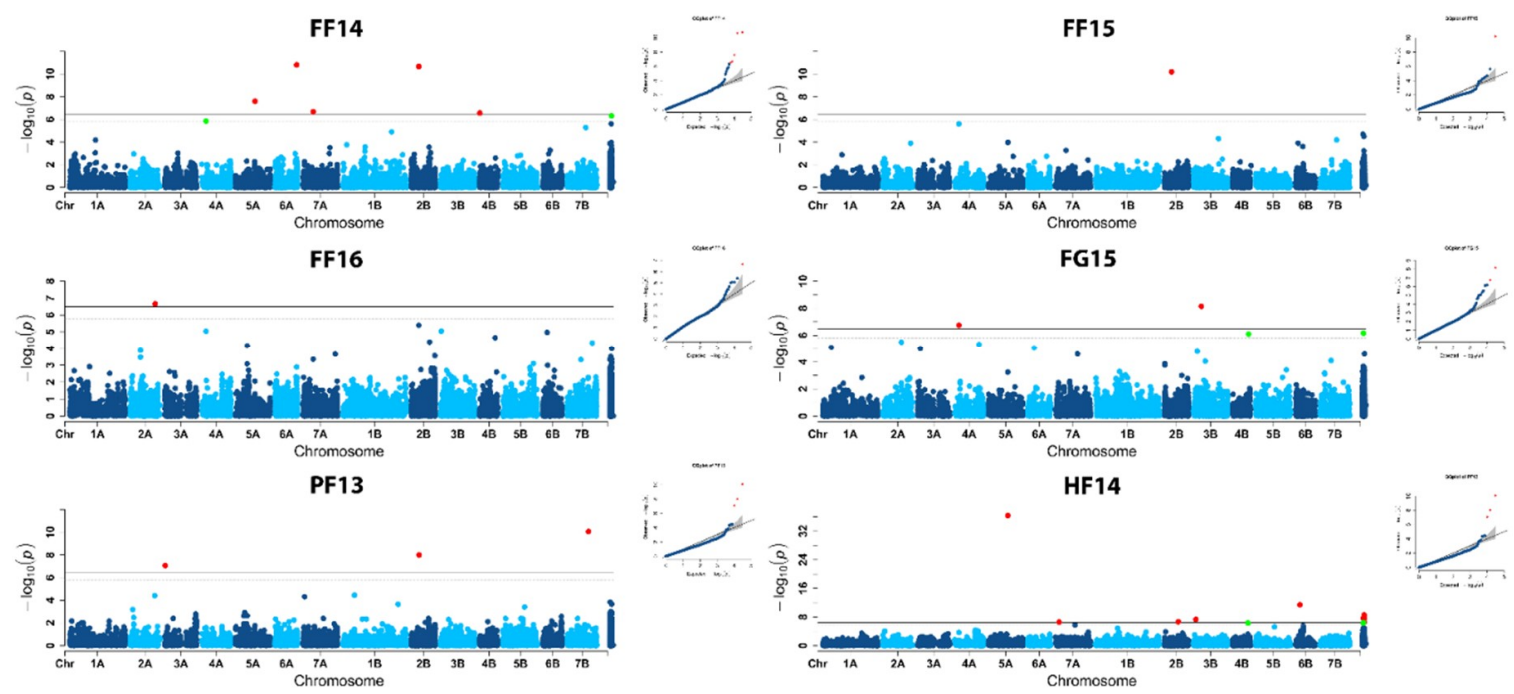

Figure 3. Manhattan plots showing the chromosome location of significant marker-trait associations for prostrate growth habit from FarmCPU analysis. Significant MTAs are highlighted in red $(p \leq 0.01)$ and green $(p \leq 0.05)$.

\subsection{Candidate genes}

The Confidence Intervals (CIs) including MTAs, calculated according to the LD decay (5 cM), were from 1.2 to $6 \mathrm{cM}$ based on the availability of marker sequences in those regions. Tables 4 and 5 , respectively, reported the physical intervals retrieved from the genome assemblies of the T. dicoccoides accession Zavitan and of the durum wheat cv Svevo corresponding to the genetic ones, the number of the annotated genes within these intervals, together with the number of related-growth habit genes, as previously described in literature. The physical intervals are very similar in both genomes in terms of size, except for chromosomes $3 \mathrm{~A}, 3 \mathrm{~B}, 4 \mathrm{~B}, 5 \mathrm{~A}$ and $6 \mathrm{~B}$, whereas the number of annotated genes in the intervals varied, particularly from 35 on $7 \mathrm{~A}$ and $7 \mathrm{~B}$ to 140 on $5 \mathrm{~A}$ on the Zavitan genome, and from 33 on $4 \mathrm{~B}$ to 461 on $4 \mathrm{~A}$ on the durum wheat genome. Generally, a higher number of genes have been found in the Svevo genome, except for the region on 4B (132.4-138 cM) for which the reverse was true. Many zinc-finger transcription factors were found on each chromosome region considered in both genomes, such as $\mathrm{C} 2 \mathrm{H} 2$ or $\mathrm{CCCH}$-domain zinc finger proteins, known to be involved in plant growth habit and in leaf angle regulation, but also ethylene-responsive transcription factors, gibberellin-regulated family proteins, MADS-box factors and genes affecting plant growth regulators (Tables 4 and 5; Supplemental Table S2). The higher numbers of trait-related genes, considering both genomes, were found on chromosomes 2A, 2B, 3B, 4A, 4B, 5A, 6A and 6B. All annotations were fully described in Supplementary Table S2, also including disease resistance proteins, factors affecting cold acclimation, kinases, transport receptors, sugar transporters, different kinds of transcription factors and genes encoding signal transduction pathway proteins. 
Table 4. Size and genes content of the physical regions retrieved from the Zavitan genome corresponding to the CIs of the MTAs identified.

\begin{tabular}{|c|c|c|c|c|c|c|c|}
\hline MTA & chr & CI (cM) & CI Start (bp) & $\begin{array}{l}\text { CI End } \\
(\mathrm{bp})\end{array}$ & $\mathrm{CI}(\mathrm{Mbp})$ & $\begin{array}{c}\text { Number of } \\
\text { Annotated } \\
\text { Genes }\end{array}$ & $\begin{array}{l}\text { Number of } \\
\text { Related-Growth } \\
\text { Habit Genes }\end{array}$ \\
\hline S1133336 & $2 \mathrm{~A}$ & $217.5-219.7$ & 734724817 & 741838496 & 7.1 & 97 & 7 \\
\hline D1202558 & $2 B$ & $60.3-64.7$ & 45229865 & 51452747 & 6.2 & 38 & 3 \\
\hline D1137224 & $2 B$ & $117.7-124.3$ & 117320738 & 149930630 & 32.6 & 73 & 5 \\
\hline D1271842 & $3 \mathrm{~A}$ & $0.6-6.5$ & 2640850 & 15387176 & 12.7 & 58 & 1 \\
\hline D1266232 & $3 B$ & $19.7-29.4$ & 4996463 & 17173269 & 12.2 & 58 & 4 \\
\hline S1049173 & $3 \mathrm{~B}$ & $68.2-75.3$ & 45389928 & 63515801 & 18.1 & 49 & 3 \\
\hline D1665929 & $4 \mathrm{~A}$ & $37.1-39.8$ & 47676808 & 77735733 & 30 & 107 & 7 \\
\hline D1110414 & $4 \mathrm{~B}$ & $0-3$ & 2180245 & 13531313 & 11.3 & 113 & 9 \\
\hline D1395268 & $4 \mathrm{~B}$ & $132.4-138$ & 657599661 & 661590000 & 5.6 & 44 & 2 \\
\hline D2276320 & $5 \mathrm{~A}$ & $164.3-168.9$ & 575035656 & 590239189 & 15.2 & 140 & 14 \\
\hline D1076422 & $6 \mathrm{~A}$ & 185.2-191.1 & 607923652 & 618547327 & 10.6 & 129 & 12 \\
\hline D2289020 & $6 \mathrm{~B}$ & $35.5-36.8$ & 32844660 & 47681687 & 14.8 & 104 & 5 \\
\hline D2295851 & $7 \mathrm{~A}$ & $31.4-38$ & 15519984 & 23593672 & 8.1 & 35 & 2 \\
\hline D1031337 & $7 \mathrm{~A}$ & $91.2-92.4$ & 50882080 & 56636443 & 5.7 & 57 & 6 \\
\hline D1112046 & $7 \mathrm{~B}$ & 181.9-188.8 & 680402861 & 698138699 & 17.7 & 35 & 3 \\
\hline
\end{tabular}

Table 5. Size and genes content of the physical regions retrieved from the durum wheat Svevo genome corresponding to the CIs of the MTAs identified.

\begin{tabular}{|c|c|c|c|c|c|c|c|}
\hline MTA & chr & CI (cM) & CI Start (bp) & $\begin{array}{l}\text { CI End } \\
\text { (bp) }\end{array}$ & $\mathrm{CI}(\mathrm{Mbp})$ & $\begin{array}{c}\text { Number of } \\
\text { Annotated } \\
\text { Genes }\end{array}$ & $\begin{array}{c}\text { Number of } \\
\text { Related-Growth } \\
\text { Habit Genes }\end{array}$ \\
\hline S1133336 & $2 \mathrm{~A}$ & $217.5-219.7$ & 739004624 & 746220682 & 7.2 & 202 & 10 \\
\hline D1202558 & $2 \mathrm{~B}$ & $60.3-64.7$ & 44096854 & 49732398 & 5.6 & 148 & 7 \\
\hline D1137224 & $2 \mathrm{~B}$ & $117.7-124.3$ & 109991884 & 143184509 & 33.2 & 358 & 20 \\
\hline D1271842 & $3 \mathrm{~A}$ & $0.6-6.5$ & 963147 & 7004107 & 6 & 196 & 5 \\
\hline D1266232 & $3 B$ & $19.7-29.4$ & 4675018 & 15213712 & 10.5 & 235 & 13 \\
\hline S1049173 & $3 B$ & $68.2-75.3$ & 49798003 & 61284099 & 11.5 & 178 & 9 \\
\hline D1665929 & $4 \mathrm{~A}$ & $37.1-39.8$ & 44642299 & 76324355 & 31.7 & 461 & 10 \\
\hline D1110414 & $4 \mathrm{~B}$ & $0-3$ & 1729305 & 13558565 & 11.8 & 281 & 11 \\
\hline D1395268 & $4 \mathrm{~B}$ & $132.4-138$ & 658918900 & 659539176 & 0.6 & 33 & 1 \\
\hline D2276320 & $5 \mathrm{~A}$ & $164.3-168.9$ & 532806577 & 556694196 & 23.9 & 419 & 14 \\
\hline D1076422 & $6 \mathrm{~A}$ & 185.2-191.1 & 602368652 & 614383914 & 12 & 325 & 17 \\
\hline D2289020 & $6 \mathrm{~B}$ & $35.5-36.8$ & 30090166 & 54319106 & 24.2 & 319 & 13 \\
\hline D2295851 & $7 \mathrm{~A}$ & $31.4-38$ & 18289584 & 27148666 & 8.8 & 240 & 9 \\
\hline D1031337 & $7 \mathrm{~A}$ & $91.2-92.4$ & 55718952 & 60630163 & 4.9 & 127 & 5 \\
\hline D1112046 & $7 \mathrm{~B}$ & 181.9-188.8 & 657142046 & 679568205 & 22.4 & 326 & 10 \\
\hline
\end{tabular}

\subsection{Search for Orthologs of the Rice Genes PROG1, LAZY1, TAC1 and SD1}

Results of BLAST search against the 'Zavitan' and 'Svevo' transcripts by using the rice protein sequences of PROG1, TAC1, LAZY1 and SD1 are summarized in Supplemental Table S3. Significant hits on chromosomes $4 \mathrm{~B}, 5 \mathrm{~A}, 5 \mathrm{~B}$ and $7 \mathrm{~A}$ of the $T$. dicoccoides genome were found to correspond to the PROG1 gene, whereas the chromosomes $3 \mathrm{~A}, 3 \mathrm{~B}, 4 \mathrm{~B}, 5 \mathrm{~A}$ and $5 \mathrm{~B}$ have been identified on the Svevo genome, in all cases with a putative function of a zinc finger protein. Only two matches have been found by blasting the LAZY1 gene sequence, in particular on chromosomes $6 \mathrm{~A}$ and $6 \mathrm{~B}$ in both genomes, being that on $6 \mathrm{~B}$ of the durum wheat genome annotated as LAZY1 protein. A similar result has been obtained for the $T A C 1$ gene, for which two transcripts have been identified in wheat on homoeologous chromosomes $5 \mathrm{~A}$ and 5B with different annotations in the two reference genomes: a vacuolar sorting factor has been identified in the Zavitan genome whereas a NAD-dependent protein deacetylase HST1-like has been annotated in the Svevo assembly. On the contrary, different matches on all chromosomes of the A and $B$ genomes have been obtained by using the rice $S D 1$ gene sequence. In all cases a putative function of 2-oxoglutarate (2OG) and Fe(II)-dependent oxygenase and gibberellin 20 oxidase 2 have been found, with some exceptions in both genomes as reported in Supplemental Table S3.

The correspondence between the physical positions of the orthologous candidates, and those of the MTAs identified in this study was then investigated. As regards the LAZY1 gene, the transcripts 
TRIDC6AG060360 and TRITD6Av1G224570, respectively identified in the Zavitan and Svevo genomes, were found to be located in the same CI of the MTA D1076422 (chromosome 6A). Interestingly, a gene annotated as LAZY1 protein was found to correspond to TRITD6Av1G224570 in the durum wheat genome. Looking at the tBLASTn results by using the SD1 gene sequence as query, the transcript TRIDC2AG072900 from the wild accession Zavitan was found in common with those identified in the CI of the MTA S1133336 mapped on chromosome 2A, and a second region was found to correspond to this gene on 4BS where the MTA D1110414 is located, based on transcripts TRIDC4BG000680, TRIDC4BG000760 and TRIDC4BG001380. In both cases, the putative function of 2-oxoglutarate (2OG) and $\mathrm{Fe}(\mathrm{II})$-dependent oxygenase was found. Correspondences from the durum wheat genome were instead based on TRITD2Av1G277680, TRITD7Av1G012460, TRITD7Av1G012600 and TRITD7Av1G013480, located in the same CIs of the MTAs identified on chromosome 2 and 7 of the A genome. For the B genome, a match on 4BS (TRITD4Bv1G001050), corresponding to the SD1 gene have been retrieved in the same CIs where the MTA D1110414 for growth habit was located. Finally, regarding TAC1 a clear correspondence was not found on both genomes, whereas the PROG1 gene produced a match on $4 \mathrm{~B}$ of the durum wheat genome around $650 \mathrm{Mb}$ (Table 3; Supplemental Tables S1 and S2). This region could correspond to the MTA identified on the same chromosome in this work, even if a very short $\mathrm{CI}$ has been obtained for it, as many markers resulted unmapped according the wheat consensus map available on the Triticarte website, and it was not possible to project them on the genomes. Thus, in some cases, when a match was obtained on the same chromosome, we cannot $a$ priori exclude a correspondence between the genes annotated in the CIs of the MTAs identified in this work and the rice candidate genes.

\section{Discussion}

The deceleration in the relative rate of increase in yields coupled with ongoing climate change and the increase in global population represents a serious challenge for wheat breeders. It is therefore necessary to explore new gene/alleles for altering plant architecture of wheat, among other traits, to break the productivity barrier and counteract the effect of climate changes in terms of scarcity of resources. During tillering stage, prostrate growth habit with a wide tiller angle, could improve the competitive ability of the main crop against weeds and reduce the percentage of water lost by soil evaporation due to better coverage, thus improving the water use efficiency [48].

In the present study we reported the genetic dissection of the prostrate/erect growth habit in a panel of 184 durum wheat genotypes, including 170 winter and 14 spring types. These genetic materials were phenotyped in different environmental conditions for average temperatures, and day-length, due to latitude and sowing dates, to identify the association between some genetic markers and the expression of tiller angle. However, the expression of the trait varied by $\mathrm{G} \times \mathrm{E}$ although at lesser extended than G. High heritability values have been observed for this trait thus contributing to the success for the QTL detection. A normal distribution for this trait and a high broad-sense heritability $(80 \%)$ was also reported in chickpea [49]. Indeed, a marker-trait association analysis has been carried out and a large number of MTAs have been identified, although few common in all environments. No common MTAs were found between the autumn sowing field trials conducted at Foggia (FF15 and FF16) and Hohenheim (HF14), probably due to the large difference in the average temperature values of the two locations and, consequently a different exposure to cold conditions that conditioned significantly the expression of prostrate growth habit [50].

As expected, the 14 genotypes identified a priori as spring types showed plant growth habits ranging from 1 (erect) to 5 (intermediate) with a mean value lower than winter durum wheat genotypes, suggesting a higher frequency of the prostrate growth habit in winter types. However, the population structure analysis divided 184 genotypes into four groups (G1, G2, G3, and G4) and spring types were clustered into group G3, showing no clear separation of winter and spring types, probably due to the low number of spring genotypes considered in the present study and/or the lack of exchange of diversity between spring and winter types in durum wheat, as previously suggested by Sieber et al. [42]. 
The phenotypic differences between the 4-group means were statistically significant, even excluding the spring types, suggesting that different classes for plant growth habit are not clear-cut, as there was a complete series of types from prostrate to erect depending upon temperature, length of day, and date of sowing.

Until today few studies have been conducted on bread wheat for this character and they were also difficult to compare with the present results. For example, Li et al. [20] centered to the Gli-A2 gliadin locus and associated to a QTL affecting prostrate growth trait. No common markers were available between the consensus wheat map and that reported by those authors, thus we cannot compare exactly the map position of the QTL. Nevertheless, the Gli-A2 locus is known to be located on the short arm of 6A whereas we report the MTA D1076422 on the long arm of chromosome 6A $(188.7 \mathrm{cM})$. Therefore, it seems located in a different region. In addition, QTLs for tiller angle have been reported, as associated to sharp eyespot resistance in wheat [51]. Out of them, one was localized on $4 \mathrm{AL}$ but no common markers have been found to verify the coincidence of the regions.

More recently, Giraldo et al. [22] evaluated a collection comprising genotypes belonging to three tetraploid wheat subspecies (durum, turgidum and dicoccum) for different agronomic traits, including the juvenile growth habit. Three classes have been reported (prostrate, intermediate and erect) and two DArT markers, wPt-6509 and wPt-1151, located on chromosome 3A and 3B, respectively, have been found to be associated to the trait. The map position of these two markers has been compared with that reported for the MTAs identified on the same chromosomes, based on the wheat consensus map available on Triticarte website. The marker wPt-6509 was absent on the wheat consensus map, therefore we used for comparison very close markers (wPt-8203 and wPt-8876), as reported by Jing et al. [52]. These markers were located at around $260 \mathrm{cM}$ on the chromosome $3 \mathrm{~A}$ of the consensus map in a different region where the MTA D1271842 $(2.7 \mathrm{cM})$ here identified, was mapped. The same was for the marker wPt-1151 located at $292.9 \mathrm{cM}$ on the 3BL of the consensus map, in a different region with respect to the MTAs identified on the same chromosome. Finally, three regions (3B, 4AL and 6BS) have been reported in bread wheat by Liu et al. [21] but no marker information was available in order to confirm our results.

The association mapping results herein obtained were compared with previous studies in which the map location of known vernalization and photoperiod genes were reported. The location of MTAs on chromosome $2 \mathrm{~B}$ in the proximity of $P p d-B 1$ gene and on chromosomes $4 \mathrm{~B}, 5 \mathrm{~A}$ and $7 \mathrm{~A}$ that harbor vernalization genes (Vrn-B2, $V r n-A 1, V r n-A 3$, respectively), demonstrated that the sensitivity to vernalization and photoperiod response are actually not only a key components of spring/winter growth habit, but they could also play an important role in the expression of the prostrate/erect trait. However, we also found MTAs for prostrate/erect growth habit in different chromosome regions as 4A, $4 \mathrm{~B}, 6 \mathrm{~A}$ and $6 \mathrm{~B}$ delaying sowing, under long day conditions and without satisfying the vernalization requirement of the plants.

Interestingly, the same MTAs associated to the trait in different growing seasons and environmental growth conditions have been identified, such as the MTA D1202558 located on chromosome 2B that has been identified in FF14 in spring sowing and in FF15 experiment, in autumn sowing. A second example was represented by the QTL region identified on chromosome $5 \mathrm{~A}$, which explained the phenotype in different growing seasons (FF14, spring sowing, no vernalization, and HF14, autumn sowing) and in environments with very different climatic conditions (HF14, and FF14, contrastingly cold and warm, respectively), thus suggesting either divergent functions for the $V R N-A 1$ gene, vernalization-dependent for flowering, and vernalization-independent for tiller angle, or the presence of tightly linked different causal genes.

The prostrate growth habit was best expressed in environments where the average temperature was lower, probably because under these conditions the vernalization requirement of genetic materials was better satisfied and the prostrate plants are less exposed to winter frosts, as shown in Hohenheim (HF14 $r=-0.61 p \leq 0.001$ ) (Supplemental Table S1). Voss-Fels et al (2018) demonstrated that VRN-A1 and $V R N-H 1$ modulated root architecture in wheat and barley. In particular, the presence of the winter 
alleles consistently reduced root angle at all growth stages under greenhouse and field conditions. Therefore, photoperiod and vernalization genes could also directly contribute to the juvenile growth habit. However, based on these results, also in case of pleiotropy, they would not be the only genes involved in determining this phenotype. Similarly, a barley genome-wide association mapping study aimed to identify loci determining juvenile growth habit has resulted in significant associations with SNPs close to these determinant genes, but not the genes themselves, thus supporting tight linkage more than pleiotropy [53].

From a positional approach, candidate genes have been proposed for most of the markers included in the confidence intervals of the MTAs, many of which selected for their putative function in plant growth and development, and similar role in other species. Many zinc finger proteins, in particular $\mathrm{C} 2 \mathrm{H} 2$ - and $\mathrm{CCCH}$-zinc finger proteins, have been identified, confirming the role of these family of transcription factors in determining the prostrate/erect growth habit, as reported in rice [15]. In addition, four candidate genes, such as major intrinsic protein, ankyrin repeat domain containing protein, ABC transporter, sucrose non-fermenting protein and B3 transcription factor, exhibiting a strong association with plant growth habit in our study were also validated in chickpea [49]. The gene encoding a ATP-binding cassette (ABC) transporter has been reported as involved in synchronizing plant growth with environmental and developmental changes [54]. The B3 transcription factor family is known to be involved in growth and development, in addition to flowering and vernalization responses in crop plants [55]. Indeed, we found these putative functions related to MTAs, in the same confidence intervals where also other putative candidates were positioned, such as $\mathrm{C} 2 \mathrm{H} 2$ zinc finger proteins, and genes affecting growth regulators have been identified. Finally, the gene encoding the ankyrin repeat domain-containing protein, known to have a role in plant morphogenesis and architecture by modulating meristematic activity of shoot apical meristem [56], has been found to be associated to MTAs for the tiller angle. Genes involved in metabolism, and disease resistance proteins have been also identified in our study, confirming results from a mass spectrometry study carried out in barley in which many proteins involved in metabolism and disease/defense-related processes have been reported as influencing the juvenile growth habit [57].

In the search for orthologs, we also confirmed that the rice genes PROG1, LAZY1, TAC1 and $S D 1$ (in turn ortholog of the barley semi-dwarf sdw1/denso gene), known to be regulators of tiller angle, are good candidates for this trait also in durum wheat. In fact, all these genes known to be regulators of the tiller angle in rice and/or in barley fall into the functional categories of the positional candidate genes identified in the present study. PROG1 encodes a $\mathrm{C} 2 \mathrm{H} 2$ zinc-finger protein [15], LAZY1 plays a negative role in polar auxin transport [14,58], and the SD1 gene with the ortholog of the $s d w 1 / d e n s o$ in barley encodes a gibberellic acid (GA)-20 oxidase enzyme [59,60], which is involved in gibberellin biosynthesis.

To the best of our knowledge, this work represents the first attempt to dissect the genetic basis of tiller angle in durum wheat by means of a genome-wide association mapping approach and could provide relevant details to select new durum wheat varieties with a plant architecture useful for improving yield under future resource-limited, agronomic and climate change scenarios. The high-quality reference sequence of the modern durum wheat cultivar Svevo [61] will also contribute to give more insight in the elucidation of the mechanisms controlling the juvenile growth habit by further studies of the candidate genes. In this new context, TILLING (Targeting Induced Local Lesions in Genomes) could represent a promising approach for gene validation studies, and for exploring the phenotypic role of the candidate genes identified in this study to identify new haplotypes controlling prostrate/erect growth habit and develop allele-specific markers for marker-assisted selection. 

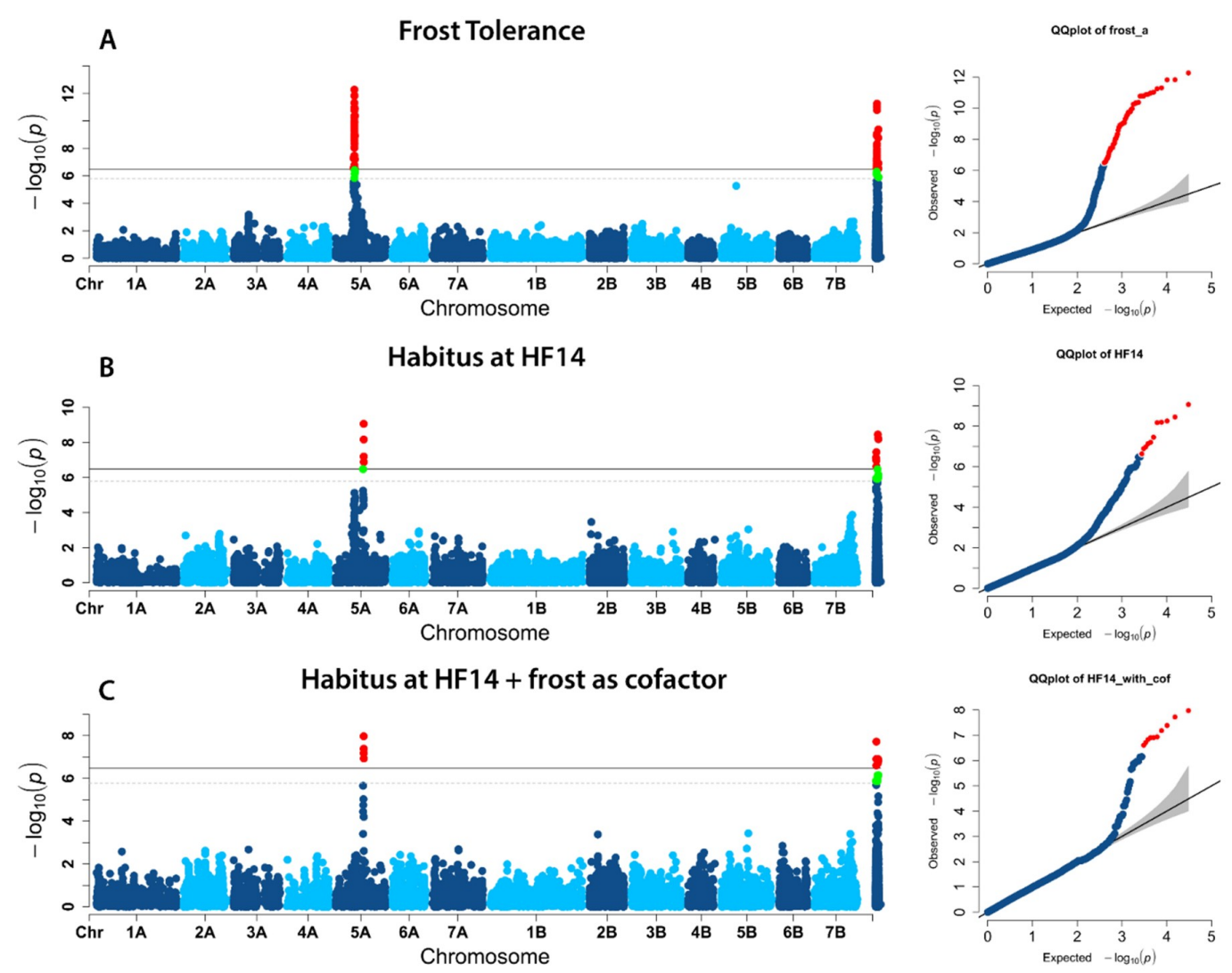

Figure 4. Manhattan plots showing the MLM analysis (using population structure and kinship as covariates) on prostrate growth habit (A) and frost tolerance (B). MLM analysis was also performed on growth habit adding the frost tolerance as a cofactor $(C)$. Significant MTAs are highlighted in red $(p \leq 0.01)$ and green $(p \leq 0.05)$.

\section{Materials and Methods}

\subsection{Plant Material}

The panel of 184 durum wheat genotypes used in this study was characterized by different geographical origins, breeding history and year of release. This panel was obtained from the State Plant Breeding Institute, University of Hohenheim, Stuttgart, Germany. Among these genotypes 170 were winter durum wheat, and the remaining 14 were spring types. The collection has been previously genotyped with DArT-seq markers, being polymorphic for 30,611 markers, as described by Sieber et al. [42]. The wheat consensus map available on the Triticarte website was considered to retrieve the genetic position of these markers.

\subsection{Field and Greenhouse Trials and Phenotyping}

The winter durum wheat panel was planted in three experimental field station: (i) at Foggia, southern Italy $\left(41^{\circ} 27^{\prime} 44.9^{\prime \prime} \mathrm{N} 15^{\circ} 30^{\prime} 03.9^{\prime \prime} \mathrm{E}\right)$, during three consecutive growing seasons (2014-2016), different growth conditions (field trial and greenhouse) and two sowing periods (autumn and spring). These experimental conditions were designed as FF14 (field trial with spring sowing on 3 April 2014 in small plots not replicated), FF15 (field trial carried out during 2014-2015 with autumn sowing on 15 December 2014 in plots with three replications), FG15 (Greenhouse experiment with winter sowing on 7 March 2015 in small plots with two replications) and FF16 (field trial carried out during 2015-2016 with autumn sowing on 7 December 2015 in plots with three replications); (ii) at Probstdorf,

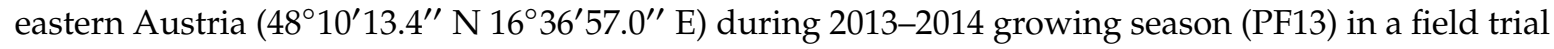
with autumn sowing and three replications; (iii) at Hohenheim, southern Germany $\left(48^{\circ} 42^{\prime} 42.2^{\prime \prime} \mathrm{N}\right.$ 
$9^{\circ} 12^{\prime} 42.5^{\prime \prime}$ E), during the growing season 2013-2014 (HF14) in field trial with no replications. The three experimental sites are characterized by contrasting climatic conditions since Foggia is characterized by a typical Mediterranean climate with mild winters and dry summers whereas Probstdorf and Hohenheim in Austria and Germany are characterized by a continental climate with cold winters (average daily temperatures around $0{ }^{\circ} \mathrm{C}$ ), and mild summers with the maximum temperatures around $22 / 24{ }^{\circ} \mathrm{C}$ in July and August. Late sowing carried out at Foggia during spring seasons (FF14 and FG15) were designed to evaluate the expression of juvenile growth habit trait excluding any natural vernalization.

The juvenile growth habit trait was estimated by measuring the tiller angle between the last developed tillers and the ground level with a protractor at the maximum tillering stage (GS25 to GS29 according to Zadoks et al. [62]) by following UPOV [63] guidelines: 1, erect; 3, semi-erect; 5 , intermediate; 7 , semi-prostrate; 9 , prostrate. Figure 5 showed the extreme phenotypes (erect and prostrate, respectively) of two genotypes as an example. In order to avoid confusion with seasonal growth habit (winter, facultative and spring type), in this paper growth habit was referred exclusively to the aptitude of the leaves and tillers to form an angle of different amplitude respect to an imaginary middle axis at tillering stage. Frost tolerance data, visually scored on a scale from 1 (no damage) to 9 (no plant survived) from the field trial conducted at Hohenheim, were used to investigate the relationships between with juvenile growth habit loci and the $\mathrm{Vrn}$ locus on chromosome 5A.
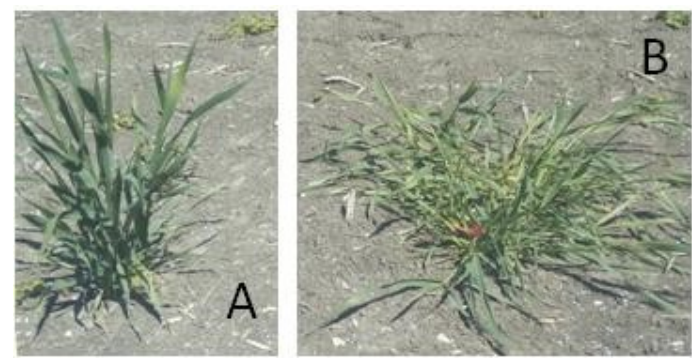

Figure 5. Examples of two genotypes of the collection used in this study, characterized by a complete erect $(\mathbf{A})$ and prostrate $(\mathbf{B})$ habit.

\subsection{Statistical Analyses}

Descriptive statistics were computed. The probability density function (PDF) of the habit by environment (i.e., location $\times$ year), mean of genotypes across sites and genotype within sites were built. Phenotypic data were analyzed using MIXED Model Equation (MME, SAS/STAT 9.2, SAS Institute Inc., Cary, NC, USA) with Residual Maximum Likelihood (REML) estimation method and growing degree days $\left(\mathrm{Tb}=0{ }^{\circ} \mathrm{C}\right)$ as a covariate. No data transformation was performed since MME can handle non-normal data and correct for heteroscedasticity [64]. Best Linear Unbiased Estimation (BLUE) and Best Linear Unbiased Predictions (BLUPs) were computed to take into account the genotype by environment interactions (GxE), according to the recommendation by Piepho et al. [65]. Broad sense heritability $\left(\mathrm{h}^{2}\right)$ was computed by solving both the MME and the General Linear Model (GLM) according to [66]. Pearson's correlations for evaluated traits among different environments were statistically analyzed at the 0.05 probability level.

\subsection{Population Structure and GWA Analyses}

The population structure was investigated using the model-based clustering method as implemented in Structure 2.3.4 [67] and the Discriminant Analysis of Principal Components (DAPC) analysis implemented in the Adegenet package for the R software (3.5.3, Version: Great Truth) [68]. We used an admixture model within the first method using the options 'correlated allele frequencies among populations' and 'infer the degree of admixture by the data'. For each $\mathrm{K}$ (number of hypothetical populations), 20 runs (burn-in length, 100,000; iterations, 100,000) were carried out, and the most likely number of $\mathrm{K}$ was determined using the method from Evanno et al. [69] as implemented in the online program STRUCTURE Harvester [70]. Both single-locus and multi-locus GWA analyses were performed 
on the 184 durum wheat genotypes using 30,475 DArT-seq markers. The prostrate/erect growth habit at the tillering stage was analysed for each single environment, as also the LSmeans obtained from across all environments. Specifically, the general linear model (GLM) and the mixed linear model (MLM) were used as implemented in GAPIT (http://zzlab.net/GAPIT; [71-73]). Then, the modified multi-locus mixed model called Fixed and random model Circulating Probability Unification (FarmCPU) (http://zzlab.net/FarmCPU; [74]) was also used for association analysis. The multi-locus methods are often used when a complex trait is under study to disentangle the role of many loci showing significant effects in the expression of a phenotype $[75,76]$. A multi-locus approach aims at enhancing the false-discovery rate and the QTL detection power by incorporating one or several markers as cofactors in a stepwise MLM, thus removing the confounding effect between testing markers and kinship [74]. Results from the different methods were compared using Quantile-Quantile (Q-Q) plots and those from FarmCPU were chosen for further discussion. The outputs obtained from GWAS by single-locus MLM were additionally presented relatively to Hohenheim, where in addition to plant growth habit, frost tolerance data were also available. Standard Bonferroni correction $(p \leq 0.05)$ were chosen to evaluate the threshold for significant associations ( $p=1.64 \mathrm{E}-06)$ and relevant MTAs were identified accordingly. Figures for GWAS results were drawn using the "A Memory-efficient, Visualization-enhanced, and Parallel-accelerated Tool for Genome-Wide Association Study" (MVP) package (https://github.com/XiaoleiLiuBio/rMVP).

\subsection{Identification of Candidate Genes}

The sequence of the significant markers identified by association mapping, as well as markers included in their CI, calculated according to the LD decay estimated by Sieber et al. [42] on the same winter durum wheat population and using the same SNP markers, were used to find positional candidate genes. The left and the right markers of the interval, together with the tagging markers when possible were based on sequence availability, and some internal markers were projected to the genome assemblies of the T. dicoccoides accession Zavitan, and of the durum wheat cultivar Svevo by a BLASTn search against their gene sets (threshold E-10) [61,77], in order to identify, by imposing functional hypotheses, candidate genes for prostrate/erect growth habit trait. All genes comprised in the LD decay intervals were retrieved with their functional annotations in the corresponding wild emmer and durum wheat genome intervals for further discussion.

\subsection{Search for Orthologous of the Rice Genes PROG1, TAC1, LAZY1, SD1 in Wheat}

The sequence of the PROG1 gene isolated in rice was retrieved by Tan et al. [15] whereas TAC1 (LOC_Os09g35980) and LAZY1 (LOC_Os11g29840) sequences were searched on the rice genome database available at http://rice.plantbiology.msu.edu/ website. A barley GA 20-oxidase gene (Hv20ox2) had been proposed as a candidate for $s d w 1 / d e n s o$, likely ortholog to rice $s d 1 / O s 20 o x 2$ gene $[23,59,60]$. For this reason, also SD1 (LOC_Os01g0883800) sequence was searched on the rice genome database. The rice protein sequences were used for a tBLASTn search against the genomes of the wild emmer wheat accession Zavitan and of the durum cultivar Svevo (threshold E-10). The physical map position of the best sequence hits was then compared to that of the MTAs identified in their LD decay intervals, to investigate the correspondence.

Supplementary Materials: The following are available online at http://www.mdpi.com/1422-0067/21/2/394/s1, Figure S1: Structure analysis divided the whole collection using 30,611 DArT-seq markers into four groups (G1, G2, G3 and G4). Admixed individuals are all grouped at the end of the bar plot. Spring types are indicated by an asterisk; Figure S2: DAPC results: (A) Number of clusters (4) at the lower BIC value; (B) Individuals in red attributed to each of the four groups; (C) Number of components to be retained for this analysis (3); Table S1:Frequencies of the habitus in the various environments; Table S2: Candidate genes for prostrate/erect growth habit trait as results of BLAST search against the "Svevo" and "Zavitan" reference genomes; Table S3: Results of BLAST search against the 'Zavitan' transcripts by using the rice protein sequences of PROG1, TAC1, LAZY1 and SD1.

Author Contributions: P.D.V. defined the research theme and supervised the project; F.H.L. and M.R. (Matthias Rapp) provided seeds of the genotypes and DArTseq markers; D.M. and P.D.V. wrote the manuscript; M.R. 
(Monica Rodriguez), S.S. and D.R. performed statistical and GWAS analyses; D.M., I.P., S.S., G.L., J.L., F.H.L. and, M.R. (Matthias Rapp) phenotyped the association mapping panel; D.M. and G.L. contributed in the candidate gene search; R.P. and N.P. contributed to interpretation and presentation; All authors have read and agreed to the published version of the manuscript.

Funding: This work was partially supported by the Italian Ministry of Agriculture (MiPAAF) under the BIODURUM project-Rafforzamento dei sistemi produttivi del grano duro biologico italiano" —DM n. 95989 22/12/2016) and by the Deutsche Forschungsgemeinschaft (DFG LO 1816-2/1, DFG LO 1816-4/1).

Acknowledgments: We would like to thank Giuseppe Petruzzino for helping in the candidate gene search and Antonio Troccoli for meteorological data support.

Conflicts of Interest: The authors declare no conflict of interest. The funders had no role in the design of the study; in the collection, analyses, or interpretation of data; in the writing of the manuscript; or in the decision to publish the results.

\section{References}

1. Sakamoto, T.; Matsuoka, M. Generating high-yielding varieties by genetic manipulation of plant architecture. Curr. Opin. Biotechnol. 2004, 15, 144-147. [CrossRef]

2. Peng, J.; Richards, D.E.; Hartley, N.M.; Murphy, G.P.; Devos, K.M.; Flintham, J.E.; Beales, J.; Fish, L.J.; Worland, A.J.; Pelica, F.; et al. Green revolution genes encode mutant gibberellin response modulators. Nature 1999, 400, 256-261. [CrossRef]

3. Donald, C.M. The breeding of crop ideotypes. Euphytica 1968, 17, 385-403. [CrossRef]

4. Intergovernmental Panel on Climate Change. Climate Change 2014 Mitigation of Climate Change; Cambridge University Press: Cambridge, UK, 2015; ISBN 9781107415416.

5. De Vita, P.; Taranto, F. Durum wheat (Triticum turgidum ssp. durum) breeding to meet the challenge of climate change. In Advances in Plant Breeding Strategies: Cereals; Al-Khayri, J.M., Jain, S., Johnson, M.D.V., Eds.; Springer International Publishing: Cham, Switzerland, 2019; Volume 5, pp. 471-524.

6. De Vita, P.; Colecchia, S.A.; Pecorella, I.; Saia, S. Reduced inter-row distance improves yield and competition against weeds in a semi-dwarf durum wheat variety. Eur. J. Agron. 2017, 85, 69-77. [CrossRef]

7. Hussien, A.; Tavakol, E.; Horner, D.S.; Muñoz-Amatriaín, M.; Muehlbauer, G.J.; Rossini, L. Genetics of tillering in rice and barley. Plant Genome 2014, 7. [CrossRef]

8. Giunta, F.; De Vita, P.; Mastrangelo, A.M.; Sanna, G.; Motzo, R. Environmental and genetic variation for yield-related traits of durum wheat as affected by development. Front. Plant Sci. 2018, 9, 8. [CrossRef] [PubMed]

9. Baum, M.; Grando, S.; Backes, G.; Jahoor, A.; Sabbagh, A.; Ceccarelli, S. QTLs for agronomic traits in the Mediterranean environment identified in recombinant inbred lines of the cross 'Arta' $\times$ H. spontaneum 41-1. Theor. Appl. Genet. 2003, 107, 1215-1225. [CrossRef] [PubMed]

10. Dong, Y.; Kamiunten, H.; Ogawa, T.; Tsuzuki, E.; Terao, H.; Lin, D.; Matsuo, M. Mapping of QTLs for leaf developmental behavior in rice (Oryza sativa L.). Euphytica 2004, 138, 169-175. [CrossRef]

11. Xu, Y.; McCouch, S.R.; Shen, Z. Transgressive segregation of tiller angle in rice caused by complementary gene action. Crop Sci. 1998, 38, 12-19. [CrossRef]

12. Yu, C.Y.; Liu, Y.Q.; Jiang, L.; Wang, C.M.; Zhai, H.Q.; Wan, J.M. QTLs mapping and genetic analysis of tiller angle in rice (Oryza sativa L.). Yi Chuan Xue Bao 2005, 32, 948-954.

13. Jin, J.; Huang, W.; Gao, J.P.; Yang, J.; Shi, M.; Zhu, M.Z.; Luo, D.; Lin, H.X. Genetic control of rice plant architecture under domestication. Nat. Genet. 2008, 40, 1365-1369. [CrossRef] [PubMed]

14. Li, P.; Wang, Y.; Qian, Q.; Fu, Z.; Wang, M.; Zeng, D.; Li, B.; Wang, X.; Li, J. LAZY1 controls rice shoot gravitropism through regulating polar auxin transport. Cell Res. 2007, 17, 402-410. [CrossRef] [PubMed]

15. Tan, L.; Li, X.; Liu, F.; Sun, X.; Li, C.; Zhu, Z.; Fu, Y.; Cai, H.; Wang, X.; Xie, D.; et al. Control of a key transition from prostrate to erect growth in rice domestication. Nat. Genet. 2008, 40, 1360-1364. [CrossRef] [PubMed]

16. Yu, B.; Lin, Z.; Li, H.; Li, X.; Li, J.; Wang, Y.; Zhang, X.; Zhu, Z.; Zhai, W.; Wang, X.; et al. TAC1, a major quantitative trait locus controlling tiller angle in rice. Plant J. 2007, 52, 891-898. [CrossRef]

17. Zhang, J.; Yang, X.; Moolhuijzen, P.; Bellgard, M.; Lance, R.; Appels, R.; Li, C. Towards isolation of the barley green revolution gene. In Proceedings of the 12th Australian Barley Technical Symposium, Hobart, Australia, 11-14 September 2005. 
18. Kuczyńska, A.; Mikołajczak, K.; Ćwiek, H. Pleiotropic effects of the sdw1 locus in barley populations representing different rounds of recombination. Electron. J. Biotechnol. 2014, 17, 217-223. [CrossRef]

19. Talamè, V.; Sanguineti, M.; Chiapparino, E.; Bahri, H.; Ben Salem, A.; Forster, B.; Ellis, R.; Rhouma, S.; Zoumarou, W.; Waugh, R.; et al. Identification of Hordeum spontaneum QTL alleles improving field performance of barley grown under rainfed conditions. Ann. Appl. Biol. 2004, 144, 309-319. [CrossRef]

20. Li, W.L.; Nelson, J.C.; Chu, C.Y.; Shi, L.H.; Huang, S.H.; Liu, D.J. Chromosomal locations and genetic relationships of tiller and spike characters in wheat. Euphytica 2002, 125, 357-366. [CrossRef]

21. Liu, Y.; Lin, Y.; Gao, S.; Li, Z.; Ma, J.; Deng, M.; Chen, G.; Wei, Y.; Zheng, Y. A genome-wide association study of 23 agronomic traits in Chinese wheat landraces. Plant J. 2017, 91, 861-873. [CrossRef]

22. Giraldo, P.; Royo, C.; González, M.; Carrillo, J.M.; Ruiz, M. Genetic diversity and association mapping for agromorphological and grain quality traits of a structured collection of durum wheat landraces including subsp. durum, turgidum and diccocon. PLoS ONE 2016, 11, e0166577. [CrossRef]

23. Jia, Q.; Zhang, X.-Q.; Westcott, S.; Broughton, S.; Cakir, M.; Yang, J.; Lance, R.; Li, C. Expression level of a gibberellin 20-oxidase gene is associated with multiple agronomic and quality traits in barley. Theor. Appl. Genet. 2011, 122, 1451-1460. [CrossRef]

24. Hashjin, J.M. Genotypic and Environmental Effects on Growth Habit in Wheat (Triticum aestivum L.): A Thesis Presented in Partial Fulfilment of the Requirements for the Degree of Master of Agricultural Science in Plant Science (Plant Breeding) at Massey University. Ph.D. Thesis, Massey University, Palmerston North, New Zealand, 1992.

25. Reynolds, M.P.; Ortiz-Monasterio, J.I.; McNab, A. Application of Physiology in Wheat Breeding; CIMMYT: Mexico City, Mexico, 2001; ISBN 970-648-077-3.

26. Roberts, D.W.A. Identification of loci on chromosome 5A of wheat involved in control of cold hardiness, vernalization, leaf length, rosette growth habit, and height of hardened plants. Genome 1990, 33, 247-259. [CrossRef]

27. Nishio, K.; Nakagawa, M.; Watanabe, S.; Gocho, H. Studies on the growth habit of wheat varieties. 4. Relation between temperature effect and photoperiodism and its effect on the growth habit of wheat. Ikushugaku Zasshi 1962, 12, 101-107. [CrossRef]

28. Zhu, C.; Gore, M.; Buckler, E.S.; Yu, J. Status and prospects of association mapping in plants. Plant Genome J. 2008, 1, 5-20. [CrossRef]

29. Canè, M.A.; Maccaferri, M.; Nazemi, G.; Salvi, S.; Francia, R.; Colalongo, C.; Tuberosa, R. Association mapping for root architectural traits in durum wheat seedlings as related to agronomic performance. Mol. Breed. 2014, 34, 1629-1645. [CrossRef]

30. Maccaferri, M.; El-Feki, W.; Nazemi, G.; Salvi, S.; Canè, M.A.; Colalongo, M.C.; Stefanelli, S.; Tuberosa, R. Prioritizing quantitative trait loci for root system architecture in tetraploid wheat. J. Exp. Bot. 2016, 67, 1161-1178. [CrossRef] [PubMed]

31. Sabiel, S.A.I.; Huang, S.; Hu, X.; Ren, X.; Fu, C.; Peng, J.; Sun, D. SNP-based association analysis for seedling traits in durum wheat (Triticum turgidum L. durum (Desf.)). Breed. Sci. 2017, 67. [CrossRef]

32. Laidò, G.; Mangini, G.; Taranto, F.; Gadaleta, A.; Blanco, A.; Cattivelli, L.; Marone, D.; Mastrangelo, A.M.; Papa, R.; De Vita, P. Genetic diversity and population structure of tetraploid wheats (Triticum turgidum L.) estimated by SSR, DArT and pedigree data. PLOS ONE 2013, 8, e67280.

33. Marone, D.; Laidò, G.; Gadaleta, A.; Colasuonno, P.; Ficco, D.B.M.; Giancaspro, A.; Giove, S.; Panio, G.; Russo, M.A.; De Vita, P.; et al. A high-density consensus map of A and B wheat genomes. Theor. Appl. Genet. 2012, 125, 1619-1638. [CrossRef]

34. Liu, W.; Maccaferri, M.; Rynearson, S.; Letta, T.; Zegeye, H.; Tuberosa, R.; Chen, X.; Pumphrey, M. Novel sources of stripe rust resistance identified by genome-wide association mapping in Ethiopian durum wheat (Triticum turgidum ssp. durum). Front. Plant Sci. 2017, 8, 774. [CrossRef]

35. Laidò, G.; Panio, G.; Marone, D.; Russo, M.A.; Ficco, D.B.M.; Giovanniello, V.; Cattivelli, L.; Steffenson, B.; De Vita, P.; Mastrangelo, A.M. Identification of new resistance loci to African stem rust race TTKSK in tetraploid wheats based on linkage and genome-wide association mapping. Front. Plant Sci. 2015, 6, 1033.

36. Aoun, M.; Breiland, M.; Kathryn Turner, M.; Loladze, A.; Chao, S.; Xu, S.S.; Ammar, K.; Anderson, J.A.; Kolmer, J.A.; Acevedo, M. Genome-wide association mapping of leaf rust response in a durum wheat worldwide germplasm collection. Plant Genome 2016, 9. [CrossRef] [PubMed] 
37. Ghavami, F.; Elias, E.M.; Mamidi, S.; Ansari, O.; Sargolzaei, M.; Adhikari, T.; Mergoum, M.; Kianian, S.F.; De Koning, D.-J. Mixed model association mapping for Fusarium head blight resistance in Tunisian-derived durum wheat populations. Genetics 2011, 1, 209-218. [CrossRef] [PubMed]

38. Laidò, G.; Marone, D.; Russo, M.A.; Colecchia, S.A.; Mastrangelo, A.M.; De Vita, P.; Papa, R. Linkage disequilibrium and genome-wide association mapping in tetraploid wheat (Triticum turgidum L.). PLoS ONE 2014, 9, e95211.

39. Mengistu, D.K.; Kidane, Y.G.; Catellani, M.; Frascaroli, E.; Fadda, C.; Pè, M.E.; Dell'Acqua, M. High-density molecular characterization and association mapping in Ethiopian durum wheat landraces reveals high diversity and potential for wheat breeding. Plant Biotechnol. J. 2016, 14, 1800-1812. [CrossRef]

40. Soriano, J.M.; Malosetti, M.; Roselló, M.; Sorrells, M.E.; Royo, C. Dissecting the old Mediterranean durum wheat genetic architecture for phenology, biomass and yield formation by association mapping and QTL meta-analysis. PLoS ONE 2017, 12, e0178290. [CrossRef] [PubMed]

41. Reimer, S.; Pozniak, C.J.; Clarke, F.R.; Clarke, J.M.; Somers, D.J.; Knox, R.E.; Singh, A.K. Association mapping of yellow pigment in an elite collection of durum wheat cultivars and breeding lines. Genome 2008, 51, 1016-1025. [CrossRef] [PubMed]

42. Sieber, A.-N.; Longin, C.F.H.; Würschum, T. Molecular characterization of winter durum wheat (Triticum durum) based on a genotyping-by-sequencing approach. Plant Genet. Resour. 2015, 15, 36-44. [CrossRef]

43. Purcell, S.; Neale, B.; Todd-Brown, K.; Thomas, L.; Ferreira, M.A.R.; Bender, D.; Maller, J.; Sklar, P.; De Bakker, P.I.W.; Daly, M.J.; et al. PLINK: A tool set for whole-genome association and population-based linkage analyses. Am. J. Hum. Genet. 2007, 81, 559-575. [CrossRef] [PubMed]

44. Maccaferri, M.; Ricci, A.; Salvi, S.; Milner, S.G.; Noli, E.; Martelli, P.L.; Casadio, R.; Akhunov, E.; Scalabrin, S.; Vendramin, V.; et al. A high-density, SNP-based consensus map of tetraploid wheat as a bridge to integrate durum and bread wheat genomics and breeding. Plant Biotechnol. J. 2015, 13, 648-663. [CrossRef] [PubMed]

45. Le Gouis, J.; Bordes, J.; Ravel, C.; Heumez, E.; Faure, S.; Praud, S.; Galic, N.; Remoué, C.; Balfourier, F.; Allard, V.; et al. Genome-wide association analysis to identify chromosomal regions determining components of earliness in wheat. Theor. Appl. Genet. 2012, 124, 597-611. [CrossRef]

46. Lowe, I.; Jankuloski, L.; Chao, S.; Chen, X.; See, D.; Dubcovsky, J. Mapping and validation of QTL which confer partial resistance to broadly virulent post-2000 North American races of stripe rust in hexaploid wheat. Theor. Appl. Genet. 2011, 123, 143-157. [CrossRef] [PubMed]

47. He, X.; Singh, P.K.; Dreisigacker, S.; Singh, S.; Lillemo, M.; Duveiller, E. Dwarfing genes Rht-B1b and Rht-D1b are associated with both type I FHB susceptibility and low anther extrusion in two bread wheat populations. PLoS ONE 2016, 11, e0162499. [CrossRef]

48. Didon, U.M.E. Variation between barley cultivars in early response to weed competition. J. Agron. Crop. Sci. 2002, 188, 176-184. [CrossRef]

49. Upadhyaya, H.D.; Bajaj, D.; Srivastava, R.; Daware, A.; Basu, U.; Tripathi, S.; Bharadwaj, C.; Tyagi, A.K.; Parida, S.K. Genetic dissection of plant growth habit in chickpea. Funct. Integr. Genom. 2017, 17, 711-723. [CrossRef] [PubMed]

50. Limin, A.E.; Fowler, D.B. Morphological and cytological characters associated with low-temperature tolerance in wheat (Triticum aestivum L. em Thell.). Can. J. Plant Sci. 2000, 80, 687-692. [CrossRef]

51. Cheng, K.; Zhao, R.; Jiang, Z.; Bie, T.; Zang, S.; Zhang, B.; Wu, X.; Gao, D.; Wu, R. Quantitative trait loci responsible for sharp eyespot resistance in common wheat CI12633. Sci. Rep. 2017, 7, 11799.

52. Jing, H.C.; Bayon, C.; Kanyuka, K.; Berry, S.; Wenzl, P.; Huttner, E.; Kilian, A.; Hammond-Kosack, K.E. DArT markers: Diversity analyses, genomes comparison, mapping and integration with SSR markers in Triticum monococcum. BMC Genom. 2009, 10, 458. [CrossRef]

53. Rostoks, N.; Ramsay, L.; MacKenzie, K.; Cardle, L.; Bhat, P.R.; Roose, M.L.; Svensson, J.T.; Stein, N.; Varshney, R.K.; Marshall, D.F.; et al. Recent history of artificial outcrossing facilitates whole-genome association mapping in elite inbred crop varieties. Proc. Natl. Acad. Sci. USA 2006, 103, 18656-18661. [CrossRef]

54. Borghi, L.; Kang, J.; Ko, D.; Lee, Y.; Martinoia, E. The role of ABCG-type ABC transporters in phytohormone transport. Biochem. Soc. Trans. 2015, 43, 924-930. [CrossRef]

55. Agarwal, P.; Kapoor, S.; Tyagi, A.K. Transcription factors regulating the progression of monocot and dicot seed development. BioEssays 2011, 33, 189-202. [CrossRef]

56. Sharma, M.; Pandey, G.K. Expansion and function of repeat domain proteins during stress and development in plants. Front. Plant Sci. 2016, 6, 1218. [CrossRef] [PubMed] 
57. Kuczyńska, A.; Kosmala, A.; Surma, M.; Adamski, T. Identification of tillering node proteins differentially accumulated in barley recombinant inbred lines with different juvenile growth habits. Int. J. Mol. Sci. 2012, 13, 10410-10423. [CrossRef] [PubMed]

58. Yoshihara, T.; Iino, M. Identification of the gravitropism-related rice gene LAZY1 and elucidation of LAZY1-dependent and-independent gravity signaling pathways. Plant Cell Physiol. 2007, 48, 678-688. [CrossRef] [PubMed]

59. Jia, Q.; Li, C.; Shang, Y.; Zhu, J.; Hua, W.; Wang, J.; Yang, J.; Zhang, G. Molecular characterization and functional analysis of barley semi-dwarf mutant Riso no. 9265. BMC Genom. 2015, 16, 927. [CrossRef] [PubMed]

60. Jia, Q.J.; Zhang, J.J.; Westcott, S.; Zhang, X.Q.; Bellgard, M.; Lance, R.; Li, C.D. GA-20 oxidase as a candidate for the semidwarf gene sdw1/denso in barley. Funct. Integr. Genom. 2009, 9, 255-262. [CrossRef] [PubMed]

61. Maccaferri, M.; Harris, N.S.; Twardziok, S.O.; Pasam, R.K.; Gundlach, H.; Spannagl, M.; Ormanbekova, D.; Lux, T.; Prade, V.M.; Milner, S.G.; et al. Durum wheat genome highlights past domestication signatures and future improvement targets. Nat. Genet. 2019, 51, 885-895. [CrossRef] [PubMed]

62. Zadoks, J.C.; Chang, T.; Konzak, C. A decimal code for the growth stages of cereals. Weed Res. 1974, 14, 415-421. [CrossRef]

63. UPOV. Durum Wheat. Guidelines for The Conduct of Tests for Distinctness, Uniformity and Stability; International Union for the Protection of New Varieties of Plants: Geneva, Switzerland, 2012.

64. Schabenberger, O. Introducing the GLIMMIX procedure for generalized linear mixed models. In Proceedings of the Thirtieth Annual SAS Users Group International Conference, Philadelphia, PA, USA, 10-13 April 2005.

65. Piepho, H.P.; Mohring, J.; Melchinger, A.E.; Buchse, A. BLUP for phenotypic selection in plant breeding and variety testing. Euphytica 2008, 161, 209-228. [CrossRef]

66. Piepho, H.-P.; Mohring, J. Computing heritability and selection response from unbalanced plant breeding trials. Genetics 2007, 177, 1881-1888. [CrossRef]

67. Pritchard, J.K.; Stephens, M.; Donnelly, P. Inference of population structure using multilocus genotype data. Genetics 2000, 155, 945-959.

68. Jombart, T.; Devillard, S.; Balloux, F. Discriminant analysis of principal components: A new method for the analysis of genetically structured populations. BMC Genet. 2010, 11, 94. [CrossRef] [PubMed]

69. Evanno, G.; Regnaut, S.; Goudet, J. Detecting the number of clusters of individuals using the software structure: A simulation study. Mol. Ecol. 2005, 14, 2611-2620. [CrossRef] [PubMed]

70. Earl, D.A.; Von Holdt, B.M. Structure Harvester: A website and program for visualizing STRUCTURE output and implementing the Evanno method. Conserv. Genet. Resour. 2012, 4, 359-361. [CrossRef]

71. Zhang, Z.; Ersoz, E.; Lai, C.-Q.; Todhunter, R.J.; Tiwari, H.K.; Gore, M.A.; Bradbury, P.J.; Yu, J.; Arnett, D.K.; Ordovas, J.M.; et al. Mixed linear model approach adapted for genome-wide association studies. Nat. Genet. 2010, 42, 355-360. [CrossRef] [PubMed]

72. Lipka, A.E.; Tian, F.; Wang, Q.; Peiffer, J.; Li, M.; Bradbury, P.J.; Gore, M.A.; Buckler, E.S.; Zhang, Z. GAPIT: Genome association and prediction integrated tool. Bioinformatics 2012, 28, 2397-2399. [CrossRef] [PubMed]

73. Wang, Q.; Tian, F.; Pan, Y.; Buckler, E.S.; Zhang, Z. A super powerful method for genome wide association study. PLoS ONE 2014, 9, e107684. [CrossRef]

74. Liu, X.; Huang, M.; Fan, B.; Buckler, E.S.; Zhang, Z. Iterative usage of fixed and random effect models for powerful and efficient genome-wide association studies. PLoS Genet. 2016, 12, e1005767. [CrossRef]

75. Segura, V.; Vilhjálmsson, B.J.; Platt, A.; Korte, A.; Seren, Ü.; Long, Q.; Nordborg, M. An efficient multi-locus mixed-model approach for genome-wide association studies in structured populations. Nat. Genet. 2012, 44, 825-830. [CrossRef]

76. Miao, C.; Yang, J.; Schnable, J.C. Optimising the identification of causal variants across varying genetic architectures in crops. Plant Biotechnol. J. 2019, 17, 893-905. [CrossRef]

77. Avni, R.; Nave, M.; Barad, O.; Baruch, K.; Twardziok, S.O.; Gundlach, H.; Hale, I.; Mascher, M.; Spannagl, M.; Wiebe, K.; et al. Wild emmer genome architecture and diversity elucidate wheat evolution and domestication. Science 2017, 357, 93-97. [CrossRef]

(C) 2020 by the authors. Licensee MDPI, Basel, Switzerland. This article is an open access article distributed under the terms and conditions of the Creative Commons Attribution (CC BY) license (http://creativecommons.org/licenses/by/4.0/). 